\title{
In the Wake of New Media \\ Connecting the Who with the How of Strategizing Communication
}

T. Gulbrandsen, Ib; Just, Sine Nørholm

\section{Document Version}

Accepted author manuscript

Published in:

International Journal of Strategic Communication

DOI:

10.1080/1553118X.2016.1150281

Publication date:

2016

\section{License}

Unspecified

Citation for published version (APA):

T. Gulbrandsen, I., \& Just, S. N. (2016). In the Wake of New Media: Connecting the Who with the How of Strategizing Communication. International Journal of Strategic Communication, 10(4), 223-237.

https://doi.org/10.1080/1553118X.2016.1150281

Link to publication in CBS Research Portal

\section{General rights}

Copyright and moral rights for the publications made accessible in the public portal are retained by the authors and/or other copyright owners and it is a condition of accessing publications that users recognise and abide by the legal requirements associated with these rights.

Take down policy

If you believe that this document breaches copyright please contact us (research.lib@cbs.dk) providing details, and we will remove access to the work immediately and investigate your claim. 


\section{In the Wake of New Media: Connecting the Who with the How of Strategizing Communication}

\section{Ib T. Gulbrandsen and Sine Nerholm Just}

Journal article (Post print version)

Cite: In the Wake of New Media: Connecting the Who with the How of Strategizing Communication. / T. Gulbrandsen, Ib; Just, Sine Norholm. In: International Journal of Strategic Communication, Vol. 10, №. 4, 2016, p. 223-237.

This is an Accepted Manuscript of an article published by Taylor \& Francis in International Journal of Strategic Communication on 19 April २०16, available online:

http://dx.doi.org/10.1080/1553118X.2016.1150281

Uploaded to Research@CBS: April २017 


\title{
In The Wake Of New Media:
}

\section{Connecting The Who With The How Of Strategizing Communication}

\begin{abstract}
In this article we argue that while there has been an intensified exploration of how organizations strategize within the field of strategic communication, there seems to be a key component missing, namely questioning who these organizations are and become in the process of strategizing. Strategic communication implicitly, perhaps even unintentionally, continues to rely on a classical understanding of organizations as "social units (or human groupings) deliberately constructed and reconstructed to seek specific goals" (Etzioni, 1964, p. 3). Assuming rather than exploring who the organization is, we argue, hinders a full exploration of how strategy works. Aiming to tackle this issue, we will first present three ways in which the classical understanding of organizations is being theoretically challenged by organization studies and empirically challenged by new media, arguing that organizations are networked, socio-material, and contingent processes of meaning formation. Then we examine how the reconceptualization of the organization influences the concept of strategic communication, advocating that strategies should be seen as collaborative and networked flows (the how) of shared decision-making by both human and non-human actors (the who). Finally, we discuss how this affects the notion of strategic action, and hence, strategic communication, asking what strategic action is and who performs it.
\end{abstract}




\section{Introduction}

In the wake of new media ${ }^{1}$ scholarly attention is increasingly turned to the ways in which we communicate about, with and within organizations. Typically, this research addresses either how the strategizing of communication is changing due to new media or more fundamentally how the lens of new media helps us realize that strategic communication has never been an instrumental and intentional exercise in the most effective transfer of information. The first strand of scholarship argues that new media create new and more complex realities of strategic communication (Macnamara \& Zerfass, 2012), for instance by enabling the organization's stakeholders to act as prosumers (e.g. Tapscott \& Williams, 2006) and (hence) challenging the organization to adopt a more dynamic positioning strategy (Lee \& Gosain, 2002; see also Anderson et al., 2013; Eggers, 2005; Golden, 2011; Li \& Bernoff, 2008; Scott, 2007). The second strand, within which this article is primarily situated, connects empirical developments with theoretical advances, often interdisciplinary in nature, with the aim of redefining strategy and strategic communication as such.

One of the more prominent examples of this is Hallahan et al.'s (2007) definition of strategic communication, which is explicitly positioned against what the authors label "the modernist approach" that views strategy as an exercise in ensuring "information transfer from the supervisor to the subordinate in order to gain compliance and to establish networks to ensure the organization's power in relation to the public" (p. 11). Instead, they argue, strategies depend on organizational and societal cultures and, hence, should not be understood as purely deliberate acts. Following this agenda-setting piece, multiple scholars have contributed to the effort of redefining strategic communication as more than or different from intentional plans. Strategic communications research, then, has aligned itself with developments within the field of communication studies in general by advocating a shift from

\footnotetext{
${ }^{1}$ Here, we draw on Manovich's (2003) tripartite definition of new media as consisting of and distinguishable by a software, a hardware and an informational dimension.
} 
an emphasis on the causal relationships between producers and consumers of communication to a concern with communication as an autonomous process that is as productive of subjects as it is produced by them (Gaggi, 1997). King (2009), for instance, argues that we need to pay more attention to the emergent properties of strategies, defining communication strategy as a "communicative construct derived from the interaction between reader/hearer response, situated context, and discursive patterns." (p. 20). Along the same lines Marchiori \& Bulgacov (2012) argue that we should see strategy as a communicational practice of and in organizations. Sandhu (2009) advocates an institutional perspective on strategy that is particularly sensitive to how contextual logics influence organizational practices. And focusing particularly on the ways in which the financial crisis has altered the contextual landscape, Mahoney (2011) calls for a 'paradigm shift' that will move strategic communication beyond short-term considerations (see also Overton-de Klerk \& Verwey, 2013).

Despite this rising acknowledgment of and contribution to the move from a substantialist to a relational theory of communication, strategic communication scholars have been curiously blind to the question of how changes in (the conceptualization of) the organization's strategic communication might also affect (the conceptualization of) the organization, and vice versa. Instead of engaging with this issue, Hallahan et al.'s (2007, p. 3) basic understanding of strategic communication as "the purposeful use of communication by an organization to fulfill its mission" seems to be the common starting point, the unspoken basic assumption, of strategic communication scholarship. Each new study provides cogent alternatives to traditional textbook definitions of strategic communication as processes of transmission (e.g. Argenti \& Forman, 2002; Tibbie, 1993), but the shared definition of strategic communication as 'purposefully used' organizational communication, we believe, leads to an implicit, perhaps even unintentional, continuation of a classical understanding of 
organizations as "social units (or human groupings) deliberately constructed and reconstructed to seek specific goals" (Etzioni, 1964, p. 3). Even the scholars who attempt to understand strategic communication as embedded in and influenced by the workings of the whole organization, share a blind spot in regards to who the organization is and, hence, leave assumptions about the strategically communicating organization as a rational and goaloriented human grouping unchallenged.

Whilst Hallahan et al's definition of strategic communication, with its implicit reliance on a definition of organization that resembles Etzioni's, is highly useful for distinguishing 'the organization' from other empirical phenomena and delineating its strategic communication from other communicative forms, we find that it contains a set of assumptions that are counterproductive to the mission of discontinuing "the modernist approach". In particular, we will argue that as strategic communication increasingly shifts from traditional mass media to new media like Google, Netflix, Wikipedia, smartphones, tablets and touchscreens, relying on the notion of organizations as 'social units', either directly or indirectly, becomes problematic for two reasons. First, it negates the more complex reality of organizations, a reality not brought about by new media, but made far more visible by new media. Second, it limits strategic communication to purposeful and deliberate communicative acts by a human actor, a limitation that ignores the way in which humans and technologies more and more often interact to produce unforeseen results.

Contrary to the traditional view, we will argue that organizations should be conceptualized as networks with fluid and shifting boundaries rather than stable entities, socio-material constructs rather than (purely) human communities, and collaboratively and continuously searching for meaning rather than deliberately and rationally fulfilling a predefined purpose. These are not novel (nor uncontested) theoretical claims (see e.g. Granovetter, 1983; Mayo, 1945; Orlikowski, 1992; Weick, 1969; Woodward, 1958), but we 
will argue that with the empirical developments of new media they are becoming increasingly hard to dispute. First, because new media allow the public to play an active role in generating content, rather than passively consuming content created by others (Harrison \& Barthel, 2009). Secondly, because new media bring the non-linear, open-ended character of communication 'in the making' to the surface: the communicative process is not defined by offline time and space (Baron, 1998; Castells, 2000; McKenna \& Bragh, 2000), but instead allows for continuous rewriting and recontextualization of what is communicated by hypertext (Gaggi, 1997) and through remediation (Deuze, 2006; Jenkins, 2006). As a consequence, we must decentre our understanding of strategic communication: rather than purposeful and deliberate top-down and inside-out processes, strategies must be seen as collaborative and networked flows of shared decision-making by both human and non-human actors. As such, strategic communication should be understood as a general potential for action as well as a specific ability to act that does not rest with individual actors, but instead flows between them as a kinetic energy, created and fuelled by the very relationships of mutual attribution it also establishes and sustains (Campbell, 2005, p. 3; Miller, 2007).

In presenting this argument, we first unfold three separate, yet interrelated, critiques of the classical understanding of organizations as distinct and distinguishable phenomena. Secondly, we discuss how this critique and redefinition of the who of organizations, influences our understanding of the how of strategic communication. And finally, we examine what consequences this redefinition has for the notion of strategic action, asking: if not a property of a purposefully acting human, then to whom does strategic communication pertain?

\section{Who are organizations?}

A classical and dominant answer is that organizations are "social units (or human groupings) 
deliberately constructed and reconstructed to seek specific goals" (Etzioni, 1964, p. 3), an answer that rests on three basic assumptions: organizations are 1) units: organized collections of parts that are highly integrated and, therefore, distinct from the environment in which they are embedded, 2) social: involving interaction between and groupings of people, 3) deliberately goal-oriented: formally, rationally and functionally structured so as to achieve specific, measured objectives.

While we find this answer problematic, a point to which we will return shortly, we do recognize its advantages and usefulness. First, it provides the basis for studying organizations as organizations; that is, as distinct and distinguishable phenomena. Although the definition is rather inclusive, it allows us to delimit 'the organization' as an empirical category; private companies, public institutions, voluntary groups, etc. are organizations; people meeting in shops, at bus stops or social gatherings are not. Secondly, it is highly useful for establishing strategic communication as a field; if and when one is able to distinguish an organization from other phenomena, then it is also possible to delineate its strategic communication from other communicative forms. Put simply, it becomes possible to establish the field on substantial grounds - as the theory and practice of the organization's communicative strategy (Conrad \& Poole, 2011). Despite the analytical and practical usefulness of reducing complexity, the definition has displayed considerable theoretical lacunae and weaknesses when applied to every-day strategizing. Why? Because there are simply more aspects of organizational life and its strategic communication than can be captured, let alone understood, through the notion of the organization as a social (that is, human) entity that acts deliberately to achieve set goals. In the following we will substantiate this claim.

\section{Organizations Are Fluid Networks, Not Stable Entities}

Understanding organizations as entities that are relatively independent of the contexts in 
which they operate means one can focus on the internal workings that could and should be attuned so as to establish the organization as one coherent collective actor. However, this closed perspective is blind to the ways in which organizations not only act within a context, but are also directly influenced and shaped by contextual factors. In order to account for the interdependencies of organizations and contexts one may conceptualize organizations as relational and dynamic, as emergent in and through their ever-shifting relations with others, as networks. Such an understanding highlights the ways in which the inside and outside of an organization not only influence each other, but are co-productive, meaning that the organization is not a stable 'thing', but continuously (re-)formed through the relations into which it enters and of which it consists (Castells, 2000). The organization is (part of) a network and it is networked.

The network(ed) organization can be defined by structure, process, and purpose (Alstyne, 1997). In terms of structure, a network organization is made up of co-specialized, possibly intangible, assets under shared control. Procedurally, a network organization constrains the actions of its members via their roles and positions within the network, while the members' influence emerges or fades with the establishment or dissolution of ties to others. And finally, a network organization presupposes a unifying purpose, since without such common purpose, members will neither find value in being part of the network, nor will they know whether and how to act to increase network(ed) value.

The network(ed) organization is thus defined by the network's own logic rather than by an external command logic - a logic that "substantially modifies the operation and outcome in processes of production" (Castells, 1996: 469). First and foremost it does so by de-centring performance and by sharing decision-making. Secondly, it exists only based on the binary code of inclusion/exclusion, meaning that the network will only include what its members find useful and necessary to achieving its goal. As such, the network is a structure 
comprised by different, but interconnected nodes, and it is this interconnectedness, the interaction, that comes to shape the network, the organization.

A main implication of this is that the boundaries between the organization and its environment become blurred, due to "the high degree of integration across formal boundaries" (Baker, 1993, p. 400). Meaning that distinguishing the organization's inside from its outside is difficult, if not out right counterproductive in terms of understanding the organization's workings. This may be most readily illustrated by considering the way in which new media enable and enhance collaboration and network formation within and (especially) between organizations (and other actors). A specific example is the French news organization Rue89. Started as an independent news website by four newspaper journalists in 2007, Rue89 was launched as a place in which readers, experts, and journalists would coparticipate in the production of news. Through the years, the content-providers of Rue 89 have developed a community that feels ownership over the website and have become involved in strategic decisions, such as the redesign of the website (Raviola \& Boczkowski, 2012). Here, new media not only challenge the conception of organizations as closed entities, but also raise the question of where organizational boundaries can be drawn, since the website and its content only exist due to the network of actors interested in producing the news.

\section{Organizations Are Socio-Material Constructs, Not Human Communities}

Another aspect of organizations that the classical definition takes for granted is that organizations are made up of relations between people (Granovetter, 1983). But while the focus on organizations as human groupings holds much explanatory as well as practical potential in pointing to the ways in which people do and live organizations together, it also exaggerates the extent to which people are able to construct their organizations freely. In so doing, it negates the influence that other actors, such as technology, traditions, buildings, and 
norms might have on the organization. Take the above-mentioned example of Rue89: if we were to understand this organization as an exclusively human grouping, focusing for instance on the different peoples' ability and power to contribute, we would neglect the possibility that the website itself - understood as the space in which news production takes place - might influence how the contributors are able to participate.

Thus, defining organizations in purely social terms blinds us to the role of the material as anything but the literal nuts and bolts of the organization. Instead, it might be more fruitful, both as an explanation and as a basis for action, to consider the ways in which matter is also a force that works on people; that is, materiality as co-constructive of organizations or, perhaps more aptly, organizations as thoroughly socio-material constructs (Orlikowski, 2007). In this vein, organizations can be defined as dynamic assemblages of human and non-human actors; that is, as "...ad hoc groupings of diverse elements, of vibrant materials of all sorts" (Bennett, 2010 , p. 23) in which no one actor is able to set the goal or determine the outcome of organizational action. Rather, "the effects generated by an assemblage are [...] emergent properties, emergent in that their ability to make something happen [...] is distinct from the sum of the vital force of each materiality considered alone" (Bennett, 2010, p. 24).

Seeing organizations as socio-material also suggests that constitutive processes of organizing and human-technology interactions are indistinguishable practices (Baptista, 2009). Here, the (technological) matter becomes “...integral to organizing, positing that the social and the material are constitutively entangled in everyday life" (Orlikowski 2007, p. 1437). Taking such a position does not privilege either the human or the material side of 'things' (in one-way interactions), nor does it link them through a form of mutual reciprocation (in two-way interactions). Instead, the social and the material are seen as coeval; "there is no social that is not also material, and no material that is not also social" (Orlikowski 2007, p. 1437). This conceptual point is highlighted and reinforced empirically as technology- 
driven modes of communication, production, and co-operation increasingly permeate all forms of organizing (Leonardi et al., 2012). An example of this is how the United Nations has started to interpret its environment though 'Big Data' rather than by means of surveys and other traditional methods. Today, the $\mathrm{UN}$ is increasingly relying on real-time digital traces such as tweets - to get feedback on whether UN policies and programs are working as planned and to monitor potential environmental and human catastrophes (Madsen, 2013). Due to the volume and velocity of the data, it must be harnessed and categorized by automated algorithms, meaning that the technology is not only used by the $\mathrm{UN}$, but becomes an active and independent co-producer of what the $\mathrm{UN}$ is.

\section{Organization Are Continuously Searching For Meaning, Not Merely Fulfilling Predefined Purposes}

The final assumption concerning organizations as rational actors that plan and conduct their business deliberately can be viewed as the centrepiece of the classical definition. Here the rational organization is both a fundamental theoretical assumption and a central practical ambition - organizations are rational and should be further rationalized (Scott, 2004). However, the idea(l) of rationality is probably also the most heavily contested element of the classical conception of organizations. If organizations are understood as networks rather than entities and socio-material networks rather than purely human communities, it becomes increasingly hard to claim that they are able to act in a deliberate, rational, and consistent way. Yes, the network that makes up the organization will share a common goal, but the goal of the network is emergent, continuously created and recreated, rather than a fixed starting point - and outcome - of the network's activities. What this means is that when we talk of an organization's goal and purpose, we are talking about a dynamic interest that unites the actors that are part of the network. This dynamic can, and often will, stabilize over time, meaning 
that the organization's aims will seem locked and sealed, but in reality this stability is an effect of a constant reaffirmation by the network's members that they share the same interest - not the cause of their commonality. As soon as the members stop sharing an interest in the active sense of constantly reminding each other of the common goal, the organization will change and ultimately dissolve.

As an alternative to the rationalist understanding of organizations, a growing number of scholars are arguing that organizations should be conceptualized as 'natural' (Scott, 2004); they are not the results of deliberately rational actions, but rather grow out of contingent, unplanned processes. This entails a focus on 'organic' and processual rather than 'mechanistic' and instrumental organizational forms, where the organization is seen as a living being or habitat in which people partake on a par with material elements rather than a thing, a machine, which people can use and optimize (Burns \& Stalker, 1961). For instance, scholars working from a practice perspective have highlighted how organizational actions are embedded, tacit, and/or emergent rather than deliberate means to an end (see inter alia Brown \& Diguid, 2000; Feldman \& Orlikowski, 2011; Gherardi, 2000; Wenger, 2000). As such, organizations are understood as constituted in and as 'becoming'; they are continuous, dynamic movements rather than beings that maintain a singular existence over time (Hernes, 2014).

At its most basic, this perspective posits that organizations, just as all other social forms, are narrated and narrating constructs (Boje, 1995; Czarniawska 1997; Gabriel 2000). While one can think of the storytelling organization as a purely human construct, the narrative approach often includes a strong focus on the media (that is, the technologies) in and through which organizational stories are told, sometimes going so far as to posit that the medium is the message (McLuhan, 1964). Our narratives, then, are fundamentally shaped by their sociomaterial contexts not only in the limited sense that socio-materiality plays a role in the stories, 
but also in the more encompassing sense that stories are shaped by their media of narration. Furthermore, the narrative approach has a strong processual streak: stories must be told and retold if they are to be (and stay) meaningful, and in the process of their retelling the stories are also continuously altered or developed. This point can be taken even further to claim that a narrative is never told by one voice and one voice only, but emerges dialogically as various voices contribute to and collaborate in the narrative flow (Bakhtin, 1986; Burke, 1941). Narrating the organization, then, is a collaborative communicative process involving anyone with a vested interest in the organization, anyone who at any point is part of the network that makes up the organization (Gioia et al., 2010; Hatch \& Schultz, 1997). This relational, backand-forth nature of social and material interaction, which Gergen calls 'confluence' (2010), defines who or what the organization is - or, rather, what its interrelations with others constantly (re-)assemble it to be. The organization becomes an assemblage in flux, a tapestry of all the symbols, signs, and actions that the organization in collaboration with its surroundings comes to collect and add to the never-ending story about itself.

Again, the theoretical challenge is mirrored/enhanced by new media developments that emphasize the collaborative as well as open-ended nature of organizational being-asbecoming. Online "the one interacts directly with the few and indirectly with the many" (author) in ways that are beyond the control of any one actor and may lead to completely unexpected results. Also, new media generally, and the internet particularly, enhance the dynamic and provisional character of 'organizing' through the possibilities of storing and recovering information; online organizing not only unfolds continuously and dynamically, but also through spatio-temporal disruptions; today, organizing not only unfolds in situ and in real time, but across extended socio-material networks that link and leap across time as well as space. This ads further complexity to - and enhances the need for a conceptualization of how organizations emerge in and as contingent processes rather than as the result of 
deliberate acts.

Some scholars have argued that this constant state of flux implies that we should no longer talk about 'organizations' as nouns (Chia \& Langley, 2004). That is, the constant inthe-making of organizations actually fails to create organizations. While we agree that it makes sense to focus on 'organizing' rather than 'organizations', this does not necessarily mean 'the death of organizations'. First, some processes do, over time, reproduce, ritualize and stabilize that which they continuously (re-)create. Second, even if such stability fails to materialize, it still makes sense to talk about organizations - not as entities, but as temporary results of constant collaborative constructions, made possible and attained by socio-material interactions (Mueller \& Whittle, 2012). Put differently, processes only become visible in and as their results - however temporary, unstable, and elusive these may be.

\section{In sum}

While initially raised as singular or isolated challenges to the classical definition of the organization, the three aspects can be - and increasingly are being - combined in order to redefine the organization as networked, socio-material, and contingent processes of meaning formation. As such, we find that a better way of defining who organizations are is to say that they are dynamic assemblages of human and non-human actors in which no one actor is able to set the goal or determine the outcome of organizational actions. As such, organizations are not stable entities; they are dynamic processes - not only in the sense that this is how organizations are formed, but more fundamentally as what they 'really' are (understood in the sense that there is no entity behind the process): being-as-becoming all the way down and at all times. There is no substance behind (or as a result of) the process; there is no 'it' to speak of or for, no thing. Rather, the organization is a continuously unfolding 'who', a collective actor continuously (re-)constituting its 'how', a process of forever (re-)inventing itself. The 
'how' and the 'who' of the organization - and, therefore, of its strategic communication become entangled to the point of being almost indiscernible from each other. The organization is how it does. It does not communicate; it is communication.

\section{Strategic Action As Relational Agency}

If we cannot assume that the organization holds a privileged position as strategic communicator, where does this leave strategic communication? First and foremost, we must broaden our understanding of strategic communication as a deliberate plan that is developed and then implemented. It is as much an emergent as it is an intentional (and linear) process; as much the ever-changing story of who we are (retrospectively) and who we want to be (prospectively) as the intended result of managerial decisions and actions. Secondly, we must decentre our understanding of strategies; rather than top-down and inside-out processes, strategies are collaborative and networked flows of shared decision-making. And finally, we must understand that strategies are not just produced by people and employed as instructions for human action; they are also enabled and constrained by technological and material artefacts - strategies themselves being material enablers and constraints on human action. By connecting the who with the how of organizational and communicative strategizing, we become aware of not just how our concrete practices of strategizing communication are influenced, but also by whom and from where strategizing can emerge.

Answering the question of what strategic communication is by saying that it is a process that reflexively and repeatedly constitutes its who as well as its how raises another issue: how are we, in this context, to understand strategic action as such? Or put differently: If we can no longer assume that strategic actions - and, by implication, strategies - are singularly attributable to an intending (organizational and/or human) agent, then how is (strategic) action possible at all? 


\section{Agency}

A way forward, in our opinion, is to turn to the concept of agency, understood as the potential for action as well as the specific ability to act that does not rest with individual actors, but instead flows between them as a kinetic energy, an energy that arises from the relationships of mutual attribution it also establishes and sustains (Campbell, 2005, p. 3; Miller, 2007). This means that we neither ascribe agency to individual actors nor locate it squarely at the level of social order. Instead we recognize it as “... a temporally embedded process of social engagement" (Emirbayer \& Mische, 1998, p. 962), where agency exists in the relational dynamics between individual actors and social structures. Agency does not have an abstract or stable form, but is constituted in and through the socio-material relations of its enactment (Pollock, 2012, p.95). The ability to act only appears in and through action.

The notion of relational agency enjoys widespread theoretical support, as may, for instance, be witnessed by the way sociological theories of agency-structure integration (say, those of Giddens, Bourdieu or Habermas, see also Emirbeyer 1997) have become a stable of undergraduate programs in both organization and communication studies. However, disagreements and difficulties arise when the theory is to be turned into frameworks for (analysing) communicative practice. Rather than focusing on relationality as such, there is a tendency to highlight one or another part of the process (Author 2016). Some researchers continue to privilege the actor as the analytical focal point (Foss, Waters \& Armada 2007, p. 206), others place agency solely at the level of 'text', understood broadly as that which acts on the communicating subject as well as his or her audience (Lundberg \& Gunn, 2005), or squarely in the context of action, where agency may be identified as the effects of the act (Rand, 2008). Other scholars foreground one relational aspect as a duality, e.g. between the actor as communicating subject and his/her audience (Leff, 2003; Leff \& Utley, 2004) or 
between the actor and the context of action (Miller, 2007; Gunn \& Cloud, 2010). The first set of conceptualizations may contribute to understanding a specific element in the relationship, but not the relationship as such. The second moves a bit further towards explaining one of the relations that may be said to constitute agency. But neither gets at actual relational agency; that is, the agency of rather than in relations (Emirbayer, 1997).

If we are to take the assumption of relational agency seriously, we must study and practice agency as the mutually constitutive relations between the 'who' and the 'how' of strategic communication as discussed above. In order to do so, however, we need specific tools for understanding and enacting relationality, and to this end we propose two analytical concepts: assemblages and affordances.

\section{Assemblages and affordances}

The notion of assemblage was introduced in the discussion of organizations as socio-material constructs, rather than human communities, where we defined it as 'ad hoc groupings of diverse elements'. This notion of assemblages, broadly speaking, and of socio-technical assemblages (STAs), more specifically, is closely associated with actor-network-theory, especially as articulated in the work of Michel Callon. Drawing on Deleuze and Guattari, Callon explains that the concept of assemblage "...conveys the idea of a combination of heterogeneous elements that have been carefully adjusted to one another" (Callon, 2007, p. 319), and these various “....arrangements [are] endowed with the capacity of acting in different ways depending on their configuration" (Callon, 2007, p. 320). Here, human actors do not hold independent agency, rather they are indispensable parts of a socio-technical assemblage, where neither humans nor technologies operate independently of each other (Çalişkan \& Callon, 2009, p. 390). It is not actors that assemble, but assemblages that act. 
The concept of assemblage, then, refers neither to a state of affairs or a statement on this state of affairs as independently existing phenomena, but emphasises the productive connection between the two (Phillips, 2006, p. 108). As Çalişkan and Callon assert, "nothing is left outside agencements [the French word for assemblage]. That is to say, there is no need for analysts to seek further explanation, because the (eventual) construction of its own meaning is by definition a part of the agencement" (2010, p. 9). The notion of assemblage moves the discussion of agency beyond the issue of individual and collective action by highlighting that "all action is collective since it is distributed; what vary are the mechanisms for attributing the source of action" (Çalişkan \& Callon, 2010, p. 10). Such "mechanisms for attributing the source of action', we suggest, may be captured and explained through the concept of affordances.

This concept was originally introduced by James Gibson (1986) and aimed at providing insight into the way people 'see' and experience the world. Gibson defined an affordance as "an action possibility available in the environment [...]" (McGrenere and Ho, 2000). As such, affordances frame, but do not determine, "the possibility of agentic action in relation to an object" (Hutchby, 2001: 444). The concept points to the importance of including materiality when seeking to understand the way in which people see and engage (strategically) with the world. Not by privileging the material, but by highlighting how affordances emerge in specific situations, with specific actors.

Put very simply, the concept of affordances allows us to understand that the manmachine relationship is not one of control (in which it could increasingly be discussed who controls whom), but one of mutual constitution. Take new media technologies such as Tripadvisor, which clearly are not just another channel through which organizations can, should or must strategically communicate with their customers, but significantly shape the organization-customer relationship. Focusing on the affordances of Tripadvisor allows us to 
begin understanding - and strategically implementing - the potential for new types of interactions, relations and categories of actors that the technology offers. Users of Tripadvisor can not only act as old-fashioned customers of hotels and other accommodations, but also as critics and amateur journalists and thereby come to make sense of their travel practices in new ways. While doing so, they may also influence the travel practices of others, contribute to the transformation of the travel industry and become part of new and old travel companies' strategic communication processes. Compared to a person travelling with a Michelin or Lonely Planet guide in his hand, a person travelling with a Tripadvisor app on her phone can circumvent both the traditional one-way communication of travel companies and hotels and the curated communication by other third party organized actors. Instead, she can base her travels on recommendations and warnings from fellow travellers, leaving established organizations without any purview on her decisions. While this may in some respects be an alluring account with its hint of individual and grassroots empowerment, it may also be cast in a darker light; as people become increasingly guided by their technologies of choice, walking around with their heads in their phones, do they really see where they are going, let alone choose their destinations? The concept of affordances, however, warns us against seeing such new media as complete game changers - whether for better or for worse. In particular, it can be noted here how the relationship between Tripadvisor and other existing organizations actually affords the organizations the possibility of developing strategies for how to e.g. recruit influencers or opinion leader, improve communication based on reviews or even work to discredit the reviews on Tripadvisor altogether.

An affordance, then, is the relationship between a human actor and a material (or technological) actor, a potential for (inter)action, but not the (inter)action itself. And combined with the notion of assemblages, one could argue that affordances are the agential conditions of possibility as established within any given assemblage and, at the same time, the 
specific ways in which an assemblage is established, maintained and reformed. This is a vital point for strategic communication to consider conceptually and apply practically, because it alters the understanding of strategic agency as a deliberate act by a purposeful actor. Strategic agency must instead be understood and practiced as relationally constituted in and through affordances (the how of strategizing) that are in turn constituted within and constitutive of assemblages (the who of strategizing).

\section{Relational agency in practice}

The dynamics of relational agency can be harnessed for strategic communication by considering communication strategy as an affordance in and of itself: First, which (inter)actions does the strategy, understood as a text (that is, a social technology or affordance) enable? Second, how does the strategy relate to other affordances within the organizational assemblage? And third, what conditions of possibility, stability and/or change do the relations between the strategy-as-affordance and the organization-as-assemblage establish? To illustrate the analytical and practical implications of these questions, let us briefly turn to an organization that has a particularly troubled history of (dis)connection between the how and the who of its strategic communication: the European Union (EU). First, the EU's textually stipulated communication strategy aims at bringing “...Europe closer to its citizens" by listening, advising and engaging (DG Communication, 2014, pp. 3-4). Thus, the strategy explicitly constitutes the EU as and in a communicative process that involves its main source of legitimation: the citizens. The assemblage invoked is one of mutual engagement between citizens and institutions, and the suggested agency is one of mutual empowerment through dialogue and debate. Turning to the second question, however, it becomes clear that the existing affordances for engagement (e.g. the official EU-website, www.europa.eu, the EU's official YouTube-channel, EUTube, and various Commissioners' 
blogs, to name but three 'new media' examples) are not actually geared to the type of citizeninvolvement, which the strategy calls for. They do not enable the envisioned mutual agency, but are primarily viewed and used as tools for disseminating information (for an overview and assessment of the EU's strategic communication initiatives, see Valentini \& Nesti (eds.), 2010). Thus, and moving to the third question, strategic visions of enhancing the legitimacy of the EU through stronger citizen-involvement are not realized because existing practices of strategizing do not empower citizens to interact in and with affordances in ways that might reconfigure the assemblage of the EU as such. In practice, the EU is not able to invite the citizens to participate in its communicative strategizing in ways that enable and incite people to become co-constitutive of the officially envisioned vibrant and lively polity. Turning to alternative affordances, e.g. community sites on Facebook and protests in the streets, the citizens continue to relate to the EU in such a way as to co-construct it as a tepid technocracy that is to be blamed for current economic problems and from which they feel socially estranged (Hobolt \& Tilley, 2014). There is a deep discrepancy, then, between the agency afforded in the EU's communication strategy and that which arises through the European institutions' strategic use of other affordances, meaning that the agential relations of the EUas-politics are detached from the agential relations of the EU-as-polity and that the assemblage of the EU is strained and disharmonious. This assemblage, in turn, makes it less likely for the existing affordances to be put to different use, for different and differently related agencies to arise, and, hence, for the EU to change its relationship with the citizens so as to become differently communicated.

The case of the EU amply illustrates that the relationship between the various participants in the assemblage that is the organization is not one of control, but of mutual (mis-)attribution. And strategy - understood as the always temporary, never complete result of strategizing rather than through the notion of a plan that still dominates the EU's and many 
other organizations' thinking about the matter - may become a central attributive tool, one that can afford better relations of mutuality. It is only through organizations' ability to invite to and stakeholders' willingness to participate in collaborative processes of strategizing that the organization becomes able to act (author). This should not, however, be understood in normative terms as an essentially parsimonious process, since any collaborative process will be marked by unequal distribution of resources (be it capital, reach, knowledge, ability, etc.) and will be driven by contestation and criticism as much as by agreement and applause. The point, then, is not to set op normative ideals, but to provide alternative conceptualizations; an organization's capacity for strategic action should no longer be seen as its direct ability to plan and realize intended goals, but as an aptitude for 'strategizing', understood as a continuous and continued ambition of designing processes (e.g. by the considered use of available affordances) that may engage internal and external stakeholders alike in the collaborative formation of the organizational assemblage. In and through such processes the organization will not just become meaningful in the communicative sense, but actually come (and continue becoming) into being as an organization.

\section{Implications}

At this point one might ask why researchers and practitioners alike continue to focus almost exclusively on the 'how' of strategizing despite the theoretical and empirical evidence pointing to the implications for the strategic 'who'. One answer, and a deceptively simple counter-question, is that if there is no 'it' with a strategy, no deliberate substance, intentionally acting in order to achieve a set goal, how can there be any strategic communication? While such (rhetorical) questions may hold a certain sway, we hope to have pointed out the limitations of continuing along the road of causality in which communicative processes are viewed as formative (and explanatory) of organizational substances. The 
specific problem with this view is that when the communicative process is viewed as resulting in (or pertaining to) an identifiable substance (the organization), too little emphasis is placed on the entanglements of organization and communication understood as equally dynamic processes of collaborative construction. This may create an illusion of the strategic communicator as a deliberate actor, but actually does not enable strategic communication. And while the strategic communication, of which we speak, may seem very different from strategic communication as traditionally defined, it is no less strategic. Rather, if one continues to practice strategic communication as a linearly developed and implemented plan, we would argue that one misses the opportunity of strategizing. Such plans may seem to place the strategic communicator and his or her organization nicely at the centre of things, neatly in control, but they are increasingly useless in a media landscape of which no one actor is fully in charge. This is not to say that plans and planning is redundant, but they are only one of many actors or elements that determine the trajectory and success of the communicated. The ability to invite to participation for instance - that is, setting up processes that will influence how others continuously talk the organizational who into being - is a much likelier route to the realization of one's strategic aims than any attempt to communicate who the organization is from an assumed position of stability.

Although the organization is decentred and multiplied, it is in no way less responsible for the process in and through which it is communicated. It is still liable in terms of what, how and with whom it communicates. For the assemblage that make up an organization to be able to communicate and coordinate work, its multiple actors/contributors carry responsibility in delivering and maintaining the assemblage. This will in some cases involve the formalization of interaction, e.g. through law, contracts, regulation and terms of services. From this follows that although organizations are embryonic, their members are still accountable for their actions. In other words, arguing that organizations are networked 
sociomaterial assemblages rather than social units does not entail understanding organizations as void of responsibility. In relation to strategic communication, in particular, one could even argue that the increased focus on collaboration, interaction, and participation heightens the level of responsibility, which the organization carries. Returning to our previous example, the (political) organization of the EU is clearly not in charge of all the communication about it; it is not in charge of who it becomes through how it is communicated. Yet it is the EU's problem that its strategy is not realized, it is accountable for its communicative failures, and responsible for seeking to correct them.

The question of responsibility is an important avenue for future research. Just as communication has been strategized it must be responsibilized. This, we suggest, will involve empirical applications of the conceptual framework we have forwarded here in order to move beyond identification of invitations to and participation in processes of strategizing and towards evaluations of these processes. The example of the EU provides an initial indication of what such studies might look like, but further work is needed, especially as regards the criteria for evaluation. What will these be in cases that are not as clear-cut as that of the EU? And how do we evaluate not only the organization's but other participants' contributions as well? And, more fundamentally, by which standards can we tell a good from a bad 'how', when we see one;? One first and tentative answer is that the proposed change of perspective will actually not lead to studies that see strategic communication as having a diminished role, but instead will enhance our awareness of the central constitutive role played by strategic communication. It will make us more rather than less aware of the importance of studying the how of strategizing, and it will provide us with means of doing so as well as evaluating what we find. Saying that agency arises in and as the relationship between affordances and assemblages is not saying that agency does not exist; rather, it provides us with means of 
practicing it, tools for analysing it, and inroads to evaluating it.

\section{Conclusion}

Whereas research on and in the broader field of organizational communication has largely discarded the notion of organizations as deliberately constructed human groupings and instead examines the various processes and actors involved in (communicatively) constituting the who of the organization (see e.g. Kuhn \& Ashcraft, 2003; McPhee \& Zau, 2000; Mumby \& Stohl, 1996; Putnam \& Nicotera, 2009), the field of strategic communication has focused almost exclusively on how organizations (communicatively) present and promote themselves. As such, being strategic is most often, intentionally or not, seen as a property of an entity (be it the organization as a whole or particular organizational members), a property used in order to achieve predefined goals. From our point of view, this means that the field of strategic communication is missing a key component in conceptualizing its domain, namely questioning not just how strategy works, but also who works strategically - asking not only how organizations communicate strategically, but also who these organizations are. To this end, we have argued that organizations should be understood as networked, socio-material, and contingent processes of meaning formation, where strategy is seen as a collaborative and networked flow of shared decision-making by both human and non-human actors.

The 'who' and the 'how' of the organization, we have argued, are fully connected, entangled to the point of indiscernibility. The organization does not communicate strategically; it is strategic communication. The consequence of this, we propose, is that strategic action must be understood as relational agency constituted in and through organizational affordances that in turn are constituted within and constitutive of organizational assemblages. Put differently, strategic communication is done by a network of 
actors (assemblages), who are enabled and constrained by potentials for action (affordances), potentials that are actualized in and through specific articulations (agency).

Current theoretical and empirical developments, then, force us to acknowledge that, borrowing Nietzsche's maxim, 'there is no doer behind the deed': there is no organization behind the strategizing; 'it' does not 'have' a strategy; strategizing does organizing. And as organizations should not be understood as the result of human and non-human actions, but instead as human and non-human actions, strategic communication should not be seen as the result of actions taken by organizations, but rather as that which a network of actors does when it strategizes.

\section{References}

Abbott, A., (2001). Chaos of Disciplines. Chicago: University of Chicago Press.

Alstyne, M. van, (1997). The State of Network Organization: A Survey in Three Frameworks, Journal of Organizational Computing and Electronic Commerce, 7, 2-3, 83-151.

Argenti, P.A. \& Forman, J., (2002). The Power of Corporate Communication. Crafting the Voice and Image of Your Business, McGraw-Hill, Boston, MA.

Baker, W.E., (1993). The Network Organization in Theory and Practice, in N. Nohria \& R.G. Eccles (eds.), Networks and Organizations, (pp. 397-429) Harvard Business School Press: Boston, MA.

Bakhtin, M. M., (1986). Speech Genres and Other Late Essays. Austin: University of Texas Press.

Baptista, J., (2009). 'Institutionalisation as a process of interplay between technology and its organisational context of use', Journal of Information Technology, 24, 305-319.

Bar, F. \& Simard, C., (2006). From Hierarchies to Network Firms, in L. A. Lievrouw \& S. Livingston (eds.) The Handbook of New Media. (pp. 350-363) London: Sage. 
Baron NS (1998) Letters by phone or speech by other means: the linguistics of e-mail. Language and Communication 18: 133-170.

Bennett, J. (2010) Vibrant Matter: A Political Ecology of Things. Duke University Press, Durham.

Boje, D., (1995). Stories of the Storytelling Organization: A Postmodern Analysis of Disney as 'Tamara-Land'. Academy of Management Journal, 38, 4, 997-1035.

Brown, J. S. \& Duguid P., (2001). Knowledge and Organization; A Social-Practice Perspective. Organization Science, 12, 2, 198-213.

Burke, K., (1941). The Philosophy of Literary Form. Berkeley: University of California Press.

Burns, T. \& Stalker, G. M., (1961). The Management of Innovation. London: Tavistock.

Çalişkan, K. \& Callon, M., (2009). Economization, part 1: shifting attention from the economy towards processes of economization. Economy and society, 38, 3, 369-398.

Çalişkan, K. \& Callon, M., (2010). Economization, part 2: a research programme for the study of markets. Economy and society, 39, (1) 1-32.

Callon, M. (2007). What does it mean to say that economics is performative? In D. MacKenzie, F. Muniesa \& L. Siu (Eds.), Do Economists Make Markets? On the Performativity of Economics (pp. 311-357). Princeton: Princeton University Press.

Campbell, K. K., (2005). “Agency: Promiscuous and Protean.” Communication and Critical/Cultural Studies, 2 (1), 1-19.

Castells, M. (2000). Materials for an Exploratory Theory of the Network Society. British Journal of Sociology, 51 (1), 5-24.

Castells, M., (1996). The Rise of the Network Society, The Information Age: Economy, Society and Culture Vol. I. Cambridge, MA; Oxford, UK: Blackwell.

Chia, R. \& Langley, A., (2004). The First Organization Studies Summer Workshop: Theorizing process in organizational research, Organization Studies, 25(8), 1486. 
Conrad, C. \& Poole, M. S., (2011). Strategic Organizational Communication: In a Global Economy, 7th Edition, Wiley-Blackwell.

Czarniawska, B., (1997). Narrating the Organization. Dramas of Institutional Identity. London: The University of Chicago Press.

De Pelsmacker, P., Geuens, M. \& Van den Bergh, J., (2010). Marketing Communications, A European Perspective. 4e, Harlow: Pearson Education.

Deuze, M. (2006) 'Participation, Remediation, Bricolage: Considering Principal Components of a Digital Culture', The Information Society 22: 63-75.

DG Communication (2014), Management Plan 2014. Retrieved from: http://ec.europa.eu/dgs/communication/pdf/comm-initiatives/managementplan2014_en.pdf

DiMaggio, P. J. \& W. W., Powell, (1983). The Iron Cage Revisited: Institutional Isomorphism and Collective Rationality in Organizational Fields. American Sociological Review, 48 (2), 147-160.

Emirbayer M., (1997). Manifesto for a relational sociology. American Journal of Sociology, 103(2), 281-317.

Emirbayer, M. \& Mische, A. (1998). What Is Agency?, The American Journal of Sociology, 103(4), 962-1023.

Etzioni, A., (1964). Modern Organizations. Englewood Cliffs: Prentice-Hall.

Feldman, M. S. \& W. J., Orlikowski, (2011). Theorizing Practice and Practicing Theory. Organization Science, 22(5), 1240-1253.

Foss, S. K., Waters, W. J. S. \& Armada B. J., (2007). Toward a Theory of Agentic Orientation: Rhetoric and Agency, Run Lola Run. Communication Theory 17 (3), 205-230.

Gabriel, Y., (2000). Storytelling in Organizations. Facts, Fictions, and Fantasies. Oxford: 
Oxford University Press.

Gaggi S (1997) From Text to Hypertext: Decentering the Subject in Fiction, Film, the Visual Arts, and Electronic Media. Philadelphia, PA: University of Pennsylvania Press.

Gaggi, S., (1997). From Text to Hypertext: Decentering the Subject in Fiction, Film, the Visual Arts, and Electronic Media. Philadelphia, PA: University of Pennsylvania Press.

Gergen, K. J., (2010). Co-construction, causality and confluence: organizing in a world without entities in T. Hernes and S. Maitlis (eds) Process, sensmaking and organizing (pp. 55-69), Oxford: Oxford University Press.

Gherardi, S., (2000). Practice-Based Theorizing on Learning and Knowing in Organizations. Organization, 7 (2), 211-223.

Gibson, J. J., (1954). The visual perception of objective motion and subjective movement, Psychological Review, 61: 304-314.

Gioia, D. A., Price, K., Hamilton, A. L. \& Thomas, J. B., (2010). Forging an Identity: An Insider-outsider Study of Processes Involved in the Formation of Organizational Identity, Administrative Science Quarterly, 55: 1-46.

Granovetter, M., (1983). The Strength of Weak Ties: A Network Theory Revisited. Sociological Theory, 1, 201-233.

Greeno, J. G., (1994). Gibson's affordances. Psychological Review, 101(2): 336-342

Gunn, J. and Cloud, D. L., (2010). Agentic Orientation as Magical Voluntarism. Communication Theory, 20: 50-78.

Hallahan, K., Holtzhausen, D., van Ruler, B., Verčič, D., \& Sriramesh, K. (2007). Defining Strategic Communication. International Journal of Strategic Communication, 1(1), 335.

Hannan, M. T. \& Freeman, J. (1977). The Population Ecology of Organizations. American 
Journal of Sociology 82(5), 929-964.

Harrison TM and Barthel B (2009) Wielding new media in Web 2.0: exploring the history of engagement with the collaborative construction of media products. New Media \& Society 11(1-2): 155-178.

Hatch, M. J. and Schultz, M., (1997). Relations between organizational culture, identity and image, European Journal of Marketing, 31, 356-365.

Hernes, T., (2014). A Process Theory of Organization. Oxford: Oxford University Press.

Hobolt, S. B. \& Tilley, J. (2014). Blaming Europe? Responsibility without Accountability in the European Union. Oxford: Oxford University Press.

Jarzabkowski, P. (2004). Strategy as Practice: Recursiveness, Adaptation, and Practices-inUse, Organization Studies 25(4), 529-60.

Jarzabkowski, P. \& Pinch, T., (2012). Sociomateriality is 'the New Black': accomplishing, repurposing, reinscripting and repairing in context. Management 16(5), 579-592.

Jarzabkowski, P., Balogun, J. \& Seidl, D. (2007) Strategizing: The Challenges of a Practice Perspective, Human Relations 60(1), 5-27.

Jenkins, H. (2006): Convergence Culture. Where Old and New Media Collide. New York: New York University Press.

Katz, E. \& Lazarsfeld, P., (1955). Personal Influence: The Part Played by People in the Flow of Mass Communications. Glencoe, IL: Free Press.

King, C. L., (2009). Emergent Communication Strategies. International Journal of Strategic Communication, 4(1), 19-38.

Kuhn, T., \& Ashcraft, K. L. (2003). Corporate scandal and the theory of the firm: Formulating the contributions of organizational communication studies. Management Communication Quarterly, 17, 20-57.

Leff, M., (2003). Tradition and Agency in the Humanistic Tradition. Philsosophy and 
Rhetoric, 36(2), 135-147.

Leff, M., \& Utley, E. A., (2004). Instrumental and Constitutive Rhetoric in Martin Luther King's 'Letter from Birmingham Jail'. Rhetoric \& Public Affairs, 7(1), 37-52.

Leonardi, P. M., Nardi, B. A. \& Kallinikos, J., (2012). Materiality and Organizing, Oxford, UK: Oxford University Press

Lundberg, C. \& Gunn J., (2005). Ouija Board, Are There Any Communications? Rhetoric Society Quarterly 35(4), 83-105.

Macnamara, J. \& A. Zerfass, (2012). Social Media Communication in Organizations: The Challenges of Balancing Openness, Strategy, and Management. International Journal of Strategic Communication, 6(4), 287-308.

Madsen, A. K., (2013). Web-Visions: Repurposing Digital Traces to Organize Social Attention. PhD-dissertation. Frederiksberg: Doctoral School of Organisation and Management Studies, Copenhagen Business School

Mahoney, J., (2011). Horizons in Strategic Communication: Theorising a Paradigm Shift. International Journal of Strategic Communication 5(3), 143-153.

Marchiori, M. \& Bulgacov, S., (2012). Strategy as Communicational Practice in Organizations. International Journal of Strategic Communication 6(3), 199-211.

Mayo, E., (1945). The Social Problems of an Industrial Civilization. Boston: Harvard University.

McKenna KYA and Bragh JA (2000) Plan 9 from cyberspace: the implications of the internet for personality and social psychology. Personality and Social Psychology Review 4(1): 57-75.

Mcluhan, M., (1964). Understanding Media: The Extensions of Man. New York: McGraw Hill.

McPhee, R. D., \& Zaug, P., (2000). The communicative constitution of organizations: A 
framework for explanation. Electronic Journal of Communication/La Revue Electronique de Communication, 10(1/2), 1-16.

Miller, C. R., (2007). What Can Automation Tell Us about Agency? Rhetoric Society Quarterly, 37 (2), 137-157.

Mueller, F. \& Whittle, A., (2012). Positioning identities through descriptions, in Schultz, M., Maguire, S., Langley, A., and Tsoukas, H. (eds) Constructing identity in and around organizations, pp. 147-179, Oxford: Oxford University Press

Mumby, D. K. \& Stohl, C., (1996). Disciplining Organizational Communication Studies. Management Communication Quarterly 10(1), 50-72.

Orlikowski, W. J. (1992). The Duality of Technology: Rethinking the Concept of Technology in Organizations. Organization Science, 3, 398-427.

Orlikowski, W. J., (2007). Sociomaterial Practices: Exploring Technology at Work, Organization Studies, 28(09), 1435-1448

Overton-de Klerk, N., \& Verwey, S., (2013). Towards an emerging paradigm of strategic communication: Core driving forces. Communicatio, 39(3), 362-382.

Phillips, J. (2006). Agencement/assemblage. Theory, Culture \& Society, 23(2-3), 108-109.

Plesner, U., \& Gulbrandsen, I. T. (2015). Strategy and new media: A research agenda. Strategic Organization. Retrieved from: http://soq.sagepub.com/content/early/2015/01/21/1476127014567849.abstract Pollock, N. (2012). Ranking Devices: The Socio-Materiality of Ranking," in Leonardi, P.M., Nardi B.A. \& Kallinikos, J. (eds.) Materiality and Organizing. Social Interaction in a Technological World., pp. 91-112, Oxford: Oxford University Press.

Putnam, L. L., \& Nicotera, A. M., (2009). Building theories of organization: The constitutive role of communication. London: Routledge. Robichaud, Rand, Erin J., (2008). An Inflammatory Fag and a Queer Form: Larry Kramer, Polemics, and 
Rhetorical Agency. Quarterly Journal of Speech 94(3), 297-319.

Raviola, E. and Boczkowski, P., (2012). Newsroom Meets Community in Journalism: An Account of Institutional Innovation in a French News Site. Paper presented at Organization Studies Winter Conference, Steamboat Springs, Colorado

Samra-Fredericks, D. (2003). Strategizing as Lived Experience and Strategist' Everyday Efforts to Shape Strategic Direction. Journal of Management Studies, 40: 141-174

Sandhu, S. (2009). Strategic Communication: An Institutional Perspective. International Journal of Strategic Communication, 3(2), 72-92.

Scott, W. R., (2004). Reflections of a half- century of organizational sociology, Annual Review of Sociology, 30 (1), 1- 21.

Shannon, C. E. \& Weaver W., (1949), The Mathematical Theory of Communication. Urbana: University of Illinois Press.

Tibbie, S., (1993). Developing communications strategy, Journal of Communication Management, 1 (4), 356-61

Torp. S. M., (2015), The Strategic Turn in Communication Science, in Holtzhausen, D. \& Zerfass, A. (eds.) The Routledge Handbook of Strategic Communication. Routledge. Valentini, C \& Nesti, G. (eds.), (2010). Public Communication in the European Union. History, Perspectives, Challenges. Newcastle upon Tyne: Cambridge Scholars Publishing.

Weick, K., (1969). The Social Psychology of Organizing. Reading: Addison-Wesley. Wenger, E., (2000). Communities of Practice and Social Learning Systems. Organization. $7(2), 225-246$.

Westley, B. H. \& MacLean, M. S., (1957). A conceptual model for communications research. Journalism Quarterly 34(1), 31-38.

Woodward, J. (1958). Management and Technology. London: Her Majesty's Stationary 
Office. 